\title{
Lipopolysaccharide Induces Both a Primary and a Secondary Phase of Sensitization in the Developing Rat Brain
}

\author{
SASKIA EKLIND, CARINA MALLARD, PERNILLA ARVIDSSON, AND HENRIK HAGBERG \\ Perinatal Center, Department of Obstetrics and Gynecology [S.E., H.H.], Institute for the Health of \\ Women and Children, Department of Physiology [S.E., C.M., P.A., H.H.], Institute of Physiology and \\ Pharmacology, Göteborg University, 41345 Göteborg, Sweden
}

\begin{abstract}
ABS
Data indicate that bacterial products in combination with
other antenatal or postnatal exposures increase the risk of peri-
natal brain injury. We have previously shown that administration
of lipopolysaccharide (LPS) 4 h before hypoxia-ischemia (HI)
increases brain injury in 7 -d-old rats. The mechanisms behind
such sensitization are unclear, but contrasts against a precondi-
tioning effect of LPS given $1-3$ d before ischemia in adult
animals. To investigate how the effects of LPS depend on the
time interval between administration and HI in the developing
brain, we evaluated the effect of varying time interval (2-72 h)
between LPS and HI, the duration of HI (20 or 50 min), and age
of the rat pups (postnatal d 4 or 7 ). Outcome was assessed by
brain injury scoring of specific regions. We found that LPS
reduced brain injury (by $78 \%$ ) when administered 24 h before 50
min of HI. However, when LPS was administered 6 h before
either 20 or 50 min of HI, brain injury was increased by $2026 \%$
and $137 \%$, respectively. Even LPS given 72 h before HI in-
creased injury, both when LPS was administered at postnatal d 4
\end{abstract}
The etiology of newborn encephalopathy is complex and many causal pathways have been suggested to operate antenatally and to interact with intrapartal and postnatal factors $(1,2)$. Antenatal infection has been identified as one cause of encephalopathy and cerebral palsy $(1,3,4)$, acting alone or in combination with other events such as potentially asphyxiating conditions during birth (5).

We previously showed that the combination of a low-dose LPS and a sub-threshold period of $\mathrm{HI}$ results in increased brain damage in 7-d-old rats, implicating that bacterial products sensitize the

Received August 9, 2004; accepted November 5, 2004.

Correspondence: Saskia Eklind, M.D., Department of Obstetrics and Gynecology, Sahlgrenska University Hospital, 41345 Göteborg, Sweden; e-mail: saskia.eklind@vgregion.se

Supported by the Swedish Medical Research Council (K2004-33X-14185-03A and K2004-33X-09455), the Åhlén Foundation, the Sven Jerring Foundation, the Magnus Bergvall Foundation, the Wilhelm and Martina Lundgren Foundation, the Linnéa and Josef Carlsson Foundation, the Frimurare Barnhus Foundation, Göteborg Medical Society, and Åke Wibergs Foundation and by grants to researchers in the public health service from the Swedish government (LUA).

DOI: 10.1203/01.PDR.0000163513.03619.8D (by $446 \%$ ) and 7 (by 77\%). In conclusion, LPS enhanced vulnerability in the developing brain both in the acute $(4-6 \mathrm{~h})$ and the chronic $(72 \mathrm{~h})$ phase after administration, whereas an intermediate interval between LPS and HI had the opposite effect. The long-term sensitizing effect of LPS has not been previously described. (Pediatr Res 58: 112-116, 2005)
Abbreviations
DAB, 3,3-diaminobenzidine
HI, hypoxia-ischemia
LPS, lipopolysaccharide
MAP-2, microtubule-associated protein-2
MCAO, middle cerebral artery occlusion
NF- $\boldsymbol{\kappa} \mathbf{B}$, nuclear factor-kappaB
PND, postnatal day
TGF- $\boldsymbol{\beta} 1$, transforming growth factor- $\beta 1$
TNF- $\alpha$, tumor necrosis factor- $\alpha$

immature brain (6). We also detected an increase in CD14 mRNA in the neonatal brain, suggesting activation of the innate immune system. Recently, we explored the effect of peripheral LPS on global gene expression in the immature CNS (unpublished observations). Multiple genes were regulated in a sequential manner with specific patterns of expression at different time points after LPS, suggesting that CNS vulnerability may depend on the time interval between LPS and the subsequent insult. Indeed, previous studies in the adult setting show that a single dose of LPS before permanent MCAO reduced brain injury when LPS was injected 2-4 d before MCAO $(7,8)$. Furthermore, it is well recognized that the neurodevelopmental stage is important for brain injury, therefore, speculatively, the age at the induction of infection could also be of importance. There is an urgent need to further explore how the sensitizing or preconditioning effects of LPS depend on the time interval between its administration and HI and age, specifically in the developing brain.

Therefore, we evaluated the effect of LPS on the immature brain by varying 1$)$ the time interval (2-72 h) between LPS and 
$\mathrm{HI}$; 2) the duration of HI (20 or $50 \mathrm{~min}$ ), and 3) the age of the rat pups (postnatal $\mathrm{d} 4$ or 7). Outcome was assessed $2 \mathrm{wk}$ after LPS exposure by both neuropathological quantification of tissue loss and injury scoring of specific brain regions.

\section{MATERIALS AND METHODS}

Wistar rat pups (Mollegaard Breeding and Research Centre A/S, Skensved, Denmark) were used in all experiments. The Animal Ethics Committee of the University of Göteborg approved all experiments. Animals were housed in accordance with the guidelines of the Animal Ethics Committee of the University of Göteborg.

Model for inducing HI. Animals were anesthetized with a combination of Enflurane, $\mathrm{N}_{2} \mathrm{O}$, and $\mathrm{O}_{2}$. Thereafter, the left common carotid artery was identified and cut between ligatures (9). Two hours after ischemia, pups were exposed to either 20 or $50 \mathrm{~min}$ of hypoxia ( $7.7 \%$ oxygen in nitrogen) in a chamber at $36^{\circ} \mathrm{C}$. After exposure to hypoxia, pups were returned to their dams.

Protocols. LPS (LPS O55:B5, $0.3 \mathrm{mg} / \mathrm{kg}$, Sigma Chemical Co., St. Louis, $\mathrm{MO})$ or $\mathrm{NaCl}(0.9 \%)$ were administered as a single dose intraperitoneally at PND 4 or PND 7. The different study groups are shown in Table 1. At 2, 6, 24, or $72 \mathrm{~h}$ after LPS or $\mathrm{NaCl}$, pups were subjected to 20 or $50 \mathrm{~min}$ of $\mathrm{HI}$, according to procedures described above. Two weeks after the induction of HI, animals were deeply anesthetized with Pentothal Natrium, $50 \mathrm{mg} / \mathrm{mL}$, and thereafter perfused intracardially with $0.9 \% \mathrm{NaCl}$ followed by $4 \%$ buffered formaldehyde. Brains were embedded in paraffin and sectioned $(5 \mu \mathrm{m})$ in the coronal plane.

Immunohistochemistry. Every 200th section was selected for neuropathological analysis, resulting in approximately seven brain levels per animal. Sections were stained with thionin/acid fuchsin (10) for morphologic analysis. Adjacent sections were stained for MAP-2 (mouse-anti-rat MAP-2, 1:2000, Sigma Chemical Co.) and immunoreactivity was visualized using DAB, as previously described (11) and used for area calculations.

Neuropathological analysis. A qualitative morphologic scoring system was used to evaluate brain damage at the seven different levels. Injury in the cerebral cortex was graded from 0 to 4 (with 0 meaning no observable damage and 4 being confluent infarction encompassing most of the hemisphere). The damage in the hippocampus, striatum, and thalamus was assessed with consideration taken to both atrophy (0-3) and cell injury/infarction (0-3) (12) The evaluation was made by an observer blinded to the different study groups. The brain tissue loss was measured on MAP-2-stained sections using the Olympus Micro Image analysis software system, version 4.0 (Olympus Optical, Tokyo, Japan). MAP-2-positive areas in both the contralateral and ipsilateral hemisphere were outlined and areas were calculated by the program. The proportion of infarction, expressed as percentage of the contralateral hemisphere, was calculated by subtracting the MAP-2-positive area of the ipsilateral hemisphere from the contralateral hemisphere and dividing by the area of the contralateral hemisphere.

The volume of tissue loss was calculated according to the Cavalieri principle, using the formula $\mathrm{V}=\Sigma \mathrm{APt}$, where $\mathrm{V}$ is the total volume expressed as $\mathrm{mm}^{3}, \Sigma \mathrm{A}$ is the sum of the areas measured, $\mathrm{P}$ is the inverse of the section sampling fraction $(1 / 200)$, and $t$ is the section thickness $(5 \mu \mathrm{m})(13)$.

Statistics. All data are expressed as mean \pm SEM. Comparison of area measurements between groups were performed using the Mann-Whitney $U$ test for unpaired groups. Fisher's exact test was used for brain injury scoring. For correction of multiple comparisons, the Bonferroni method was used. Significant changes were accepted at the level of $p<0.05$.

\section{RESULTS}

\section{Induction of HI 2 and $6 \mathrm{~h}$ after LPS Administration}

\section{LPS administered at PND 7 in combination with 20 min}

$\boldsymbol{H I}$. The volume of brain damage was substantially increased in the LPS $6 \mathrm{~h} / 20 \mathrm{~min} \mathrm{HI}\left(91.4 \pm 10.6 \mathrm{~mm}^{3}\right)$ group versus $\mathrm{NaCl} / 20 \min \mathrm{HI}\left(4.3 \pm 1.7 \mathrm{~mm}^{3}\right)(p<0.01)$ (Fig. $\left.1 A\right)$, and injury scores in the cerebral cortex and striatum were higher in LPS $6 \mathrm{~h} / 20 \mathrm{~min}$ HI animals (Fig. 1B). LPS pretreatment given $2 \mathrm{~h}$ before $20 \mathrm{~min} \mathrm{HI}$ did not result in brain injury (Fig. 1). There was an increased mortality in the LPS $6 \mathrm{~h} / 20 \mathrm{~min}$ HI group $(6 / 11)$ compared with controls $(0 / 11)(p<0.01)$. No difference in mortality was found between LPS $2 \mathrm{~h} / 20 \mathrm{~min} \mathrm{HI}$ and the control group.

LPS administered at PND 7 in combination with 50 min HI. The volume tissue loss was more pronounced in the group exposed to LPS $6 \mathrm{~h} / 50 \mathrm{~min} \mathrm{HI}\left(189.5 \pm 29.6 \mathrm{~mm}^{3}\right)$ compared with $\mathrm{NaCl} / 50 \mathrm{~min} \mathrm{HI}\left(79.8 \pm 14.9 \mathrm{~mm}^{3}\right)(p<0.01)$, and a similar trend was found in the evaluations of infarction area at different section levels and brain regions. No significant differences were found in the examined brain regions comparing LPS $2 \mathrm{~h} / 50 \mathrm{~min} \mathrm{HI}$ and $\mathrm{NaCl} / 50 \mathrm{~min} \mathrm{HI}$. In animals subjected to $50 \mathrm{~min}$ of $\mathrm{HI}$, there was an increased mortality rate in the

Table 1. Study groups

\begin{tabular}{|c|c|c|c|c|}
\hline Study groups & $\begin{array}{c}\text { Treated } \\
\text { animals }(n)\end{array}$ & $\begin{array}{c}\text { Age } \\
\text { (postnatal day) } \\
\text { at pretreatment }\end{array}$ & $\begin{array}{l}\text { Interval (h) } \\
\text { between pre-treatment } \\
\text { and } \mathrm{HI}\end{array}$ & $\begin{array}{c}\text { Duration of } \\
\text { HI (min) }\end{array}$ \\
\hline LPS2h/20minHI & 11 & 7 & 2 & 20 \\
\hline LPS6h/20minHI & 11 & 7 & 6 & 20 \\
\hline LPS6h/50minHI & 12 & 7 & 6 & 50 \\
\hline $\mathrm{NaCl} 4 \mathrm{~h} / 20 \mathrm{minHI}$ & 10 & 7 & 4 & 20 \\
\hline LPS24h/50minHI & 13 & 7 & 24 & 50 \\
\hline $\mathrm{NaCl} 24 \mathrm{~h} / 20 \mathrm{minHI}$ & 11 & 7 & 24 & 20 \\
\hline $\mathrm{NaCl} 24 \mathrm{~h} / 50 \mathrm{minHI}$ & 11 & 7 & 24 & 50 \\
\hline LPS72h/20minHI & 13 & 7 & 72 & 20 \\
\hline LPS72h/50minHI & 12 & 7 & 72 & 50 \\
\hline $\mathrm{NaCl} 72 \mathrm{~h} / 20 \mathrm{minHI}$ & 9 & 7 & 72 & 20 \\
\hline $\mathrm{NaCl} 72 \mathrm{~h} / 50 \mathrm{minHI}$ & 11 & 4 & 72 & 50 \\
\hline
\end{tabular}

Protocol for the 18 study groups. Pretreatment with intraperitoneal injection of LPS $(0.3 \mathrm{mg} / \mathrm{kg})$ or saline $(\mathrm{NaCl})$. The age at LPS treatment was either postnatal d 4 or 7. The interval between pretreatment (LPS or $\mathrm{NaCl}$ ) and hypoxia-ischemia (HI) as well as the duration of $\mathrm{HI}$ are given in the table. 
A
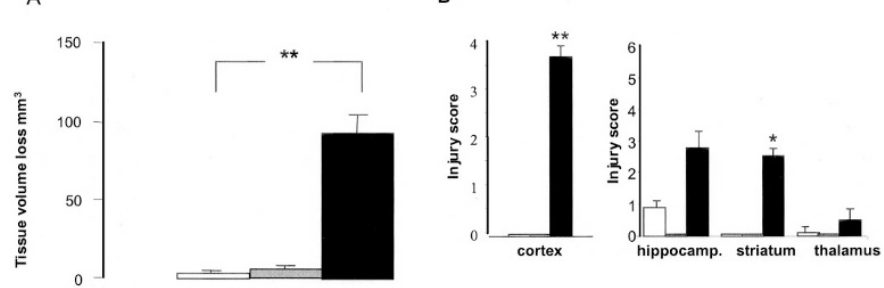

Figure 1. Time interval of 2 and $6 \mathrm{~h}$ between LPS and $20 \mathrm{~min}$ of hypoxia. Brain injury in rats pretreated with LPS $(0.3 \mathrm{mg} / \mathrm{kg})$ at PND 7, 2 and $6 \mathrm{~h}$ before 20 min of $\mathrm{HI}$ compared with $\mathrm{NaCl}$. (A) Brain damage was quantified as volume of tissue loss according to the Cavalieri principle, where the total volume is expressed as cubic millimeters. (B) Neuropathological scoring of HI brain injury in cerebral cortex (0-4), hippocampus, striatum, and thalamus (0-6). $\square$ $\mathrm{NaCl} / 20 \mathrm{minHl} n=10 ; \square \mathrm{LPS} 2 \mathrm{~h} / 20 \mathrm{minHl} n=11$; $\mathbf{L P S} 6 \mathrm{~h} / 20 \mathrm{minHl}$ $n=11$.Values are given as mean $\pm \operatorname{SEM}(* * p<0.01, * p<0.05)$.

LPS $6 \mathrm{~h} / 50 \mathrm{~min}$ HI group (8/12) compared with PND 7 controls $(1 / 11)(p<0.01)$.

\section{Induction of HI $24 \mathrm{~h}$ after LPS Administration}

LPS administered at PND 7 in combination with 20 min

HI. The brain tissue volume loss was not different in the group pretreated with LPS and subjected to $20 \mathrm{~min}$ of HI $(2.3 \pm 1.1$ $\mathrm{mm}^{3}$ ) compared with $\mathrm{NaCl} / 20 \mathrm{~min} \mathrm{HI}\left(4.7 \pm 2.5 \mathrm{~mm}^{3}\right)$, and there were no differences in regional damage between the groups.

LPS administered at PND 7 in combination with $50 \mathrm{~min}$ HI. Brain damage was significantly reduced in the LPS $24 \mathrm{~h} / 50$ min HI group $\left(15.6 \pm 7.6 \mathrm{~mm}^{3}\right)$ versus $\mathrm{NaCl}$-treated controls $\left(71.6 \pm 10.1 \mathrm{~mm}^{3}\right)(p<0.001)$ (Fig. $\left.2 A\right)$. There was also a regional reduction in brain injury in the cortex $(p<0.05)$, hippocampus $(p<0.05)$, and striatum $(p<0.05)$ in LPS 24 $\mathrm{h} / 50$ min HI compared with controls (Fig. $2 B$ ). There was no difference in mortality rate between study groups.

\section{Induction of HI $72 \mathrm{~h}$ after LPS Administered at PND 7}

LPS administered at PND 7 in combination with 20 min HI. There were no differences with respect to total brain tissue loss between the LPS $72 \mathrm{~h} / 20 \mathrm{~min} \mathrm{HI}\left(12.3 \pm 3.9 \mathrm{~mm}^{3}\right)$ and the $\mathrm{NaCl} 72 \mathrm{~h} / 20 \mathrm{~min} \mathrm{HI}\left(18.3 \pm 5.5 \mathrm{~mm}^{3}\right)$ groups. Neither were there any differences with regard to regional injury scores.

LPS administered at PND 7 in combination with $50 \mathrm{~min}$ HI. On the other hand, in rat pups subjected to $50 \mathrm{~min}$ of $\mathrm{HI}$, there was an increased tissue volume loss in the LPS- versus $\mathrm{NaCl}$-pretreated group $\left(125.3 \pm 11.9 \mathrm{~mm}^{3}\right.$ and $70.5 \pm 9.9$ $\mathrm{mm}^{3}$, respectively) $(p<0.001)$ (Fig. $\left.3 A\right)$. There was also a regional difference with increased injury scores in the cortex ( $p$ $<0.05)$ and hippocampus $(p<0.05)$ in the LPS $72 \mathrm{~h} / 50 \mathrm{~min}$ $\mathrm{HI}$ group compared with $\mathrm{NaCl} 72 \mathrm{~h} / 50$ min $\mathrm{HI}$ (Fig. $3 B$ ). There were no differences in mortality rate in the study groups.

\section{Induction of HI $72 \mathrm{~h}$ after LPS Administered at PND 4}

LPS administered at PND 4 in combination with 20 min HI. Brain tissue volume loss was more pronounced in the LPS $72 \mathrm{~h} / 20 \mathrm{~min}$ HI group $\left(27.3 \pm 7.7 \mathrm{~mm}^{3}\right)$ compared with $\mathrm{NaCl} / 20 \min \mathrm{HI}\left(5.0 \pm 1.1 \mathrm{~mm}^{3}\right)(p<0.05)$ (Fig. $\left.4 A\right)$. There
A

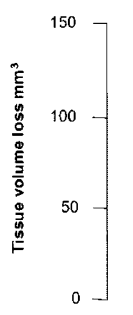

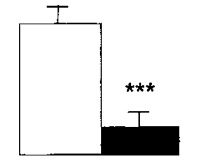
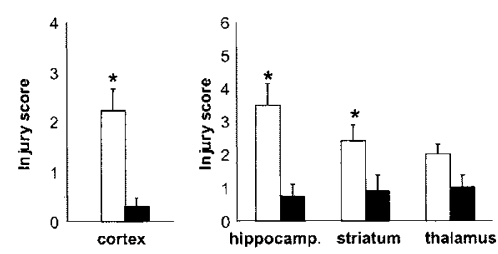

Figure 2. Time interval of $24 \mathrm{~h}$ between LPS and $50 \mathrm{~min}$, of hypoxia. Brain injury in rats pretreated with LPS $(0.3 \mathrm{mg} / \mathrm{kg})$ at PND 7, $24 \mathrm{~h}$ before $50 \mathrm{~min}$ of $\mathrm{HI}$ compared with $\mathrm{NaCl}$. (A) Brain damage was quantified as volume of tissue loss according to the Cavalieri principle, where the total volume is expressed as cubic millimeters. (B) Neuropathological scoring of HI brain injury in cerebral cortex $(0-4)$, hippocampus, striatum, and thalamus $(0-6)$. $\square$ $\mathrm{NaCl} 24 \mathrm{~h} / 50 \mathrm{minHl} n=11$; $\mathbf{L P S} 24 \mathrm{~h} / 50 \mathrm{minHl} n=11$. Values are given as mean $\pm \operatorname{SEM}(* * * p<0.001, * p<0.05)$.

was an increased injury in the cortex, striatum, and thalamus after LPS pretreatment compared with controls $(p<0.05)$ (Fig. $4 B)$.

LPS administered at PND 4 in combination with 50 min HI. After $50 \mathrm{~min}$ of HI, there were no differences in total brain tissue loss between the LPS $72 \mathrm{~h} / 50 \mathrm{~min} \mathrm{HI}\left(83.4 \pm 12.1 \mathrm{~mm}^{3}\right)$ and the $\mathrm{NaCl} 72 \mathrm{~h} / 50 \mathrm{~min} \mathrm{HI}\left(78.9 \pm 10.6 \mathrm{~mm}^{3}\right)$ groups or in injury score in any brain region. There was no difference in mortality rate in study or control groups exposed to 20 or 50 min of HI.

\section{DISCUSSION}

This is the first study in neonatal animals investigating CNS responses when both the interval between LPS and HI, and the duration of the $\mathrm{HI}$ insult were varied. The results demonstrate that the temporal relationship between LPS and the subsequent $\mathrm{HI}$ is critical. When LPS was administered $24 \mathrm{~h}$ before HI, brain injury was reduced, which agrees with several experimental studies on preconditioning in the adult brain $(8,14,15)$. Interestingly, a 72-h interval between LPS and HI resulted in enhanced brain injury, which is a similar response as when HI is induced shortly (4-6 h) after LPS. Such a long-term sensitizing effect of LPS has not previously been described for the developing brain and disagrees with reports in adult animals $(7,8,16,17)$.

We found that a 2-h delay between LPS and HI did not affect CNS susceptibility, whereas a 4- to 6-h interval efficiently sensitized the neonatal brain to injury. LPS induces systemic inflammation, which triggers NF- $\kappa \mathrm{B}$ activation in the CNS with subsequent production of chemokines and cytokines (1820). Similarly, in a recently performed microarray analysis of gene expression in the neonatal brain after LPS, we found an early inflammatory response with a marked up-regulation of chemokines (IP-10, MCP-1, and interferon-inducible protein variant 10), cytokines (IL-4 and IL-6 receptor and LPSinduced TNF- $\alpha$ ) and other inflammatory mediators like CD14 (unpublished observations). In addition, we found an early up-regulation of several pro-apoptotic genes, such as TNF receptor superfamily, member 1a (Tnfr1), galectin-9, and STAT1 at $6 \mathrm{~h}$, but to a much lesser extent at $2 \mathrm{~h}$. Such an early 
A
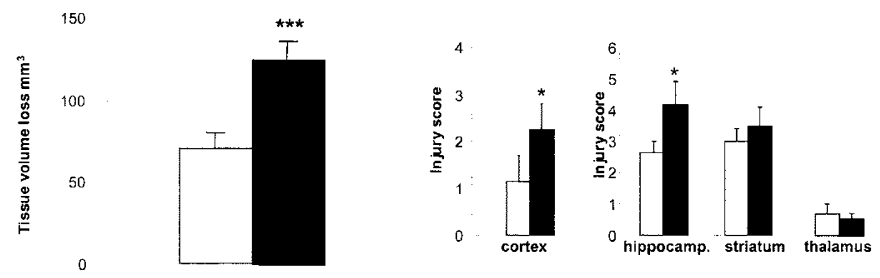

Figure 3. Time intervals of $72 \mathrm{~h}$ between LPS at PND 7 and $50 \mathrm{~min}$ of hyposia. Brain injury in rats pretreated with LPS $(0.3 \mathrm{mg} / \mathrm{kg})$ at PND $7,72 \mathrm{~h}$ before 50 min of $\mathrm{HI}$ compared with $\mathrm{NaCl}$. (A) Brain damage was quantified as volume of tissue loss according to the Cavalieri principle, where the total volume is expressed as cubic millimeters. (B) Neuropathological scoring of $\mathrm{HI}$ brain injury in cerebral cortex $(0-4)$, hippocampus, striatum, and thalamus (0-6). $\square \mathrm{NaCI} 72 \mathrm{~h} / 50 \operatorname{minHI}, n=12$; $\boldsymbol{\square}$ LPS72h/50minHI, $n=12$. Values are given as mean \pm SEM $(* * * p<0.001, * p<0.05)$.

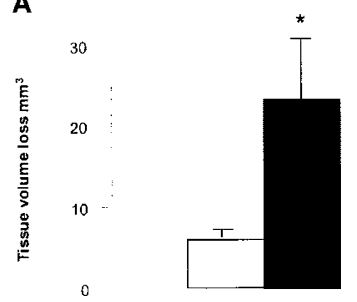

B

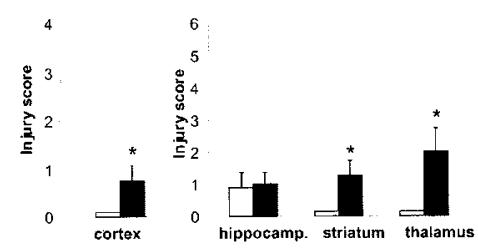

Figure 4. Time interval of $72 \mathrm{~h}$ between LPS at PND 4 and $20 \mathrm{~min}$ of hyposia. Brain injury in rats pretreated with LPS $(0.3 \mathrm{mg} / \mathrm{kg})$ at PND $4,72 \mathrm{~h}$ before 20 min of $\mathrm{HI}$, compared with $\mathrm{NaCl}$. (A) Brain damage was quantified as volume of tissue loss according to the Cavalieri principle, where the total volume is expressed as cubic millimeters. $(B)$ Neuropathological scoring of HI brain injury in cerebral cortex $(0-4)$, hippocampus, striatum, and thalamus $(0-6)$. $\square \mathrm{NaCI} 72 \mathrm{~h} / 20 \mathrm{minHI}, n=10$; $\mathbf{L P S} 72 \mathrm{~h} / 20 \mathrm{minHI}, n=11$. Values are given as mean $\pm \operatorname{SEM}(* p<0.05)$

inflammatory and apoptotic response could help to explain the primary sensitizing effect of LPS found in the immature brain in vivo $(6,21-23)$. We also found that LPS sensitized the immature brain if given $72 \mathrm{~h}$ before HI either at PND 4 or PND 7. This is interesting in that the animals have completely recovered from the systemic effects of LPS after 3 d. Early physiologic changes found after LPS injection, related to blood glucose, heart rate, temperature, and behavior, returned to normal after $3 \mathrm{~d}(24-26)$. We found no mortality after $\mathrm{HI}$ in this group. A persistently increased expression of TNF- $\alpha$, nitric oxide, and prostaglandin $\mathrm{E}_{2}$ has been observed in microglia cultures $72 \mathrm{~h}$ after LPS (27). In addition, a secondary inflammatory gene response was detected $72 \mathrm{~h}$ after LPS in neonatal rats (unpublished observations). There was a difference in the sensitizing effect of LPS between PND 4 and PND 7 rats in that the younger animals demonstrated increased brain injury after 20 min HI, whereas sensitization was observed after 50 min HI in PND 7 rats. These results emphasize the complexity of the interaction between LPS and HI and demonstrate the importance of both the intensity of the HI insult and the developmental stage of the animals.

Hypothetically, LPS, in addition to the initial primary phase of inflammation, also induces a secondary chronic state of inflammation in the developing brain, which could confer heightened vulnerability. The long-lasting effect of a low dose of endotoxin is intriguing and further studies are needed to

investigate the duration of this sensitizing effect. Hence, it was recently demonstrated that intrauterine LPS can induce a progressive degeneration of dopamine neurons that leads to permanent brain injury still present in 16-mo-old rats (28) Such long-lasting adverse CNS effects of bacterial products may have important implications in understanding the full consequences of intrauterine infections.

The preconditioning effect that was achieved when LPS was administered $24 \mathrm{~h}$ before $\mathrm{HI}$ was in agreement with previous studies on hypoxic preconditioning in 7-d-old rats that also require a 24 -h interval between the preconditioning stimulus and HI (29), as well as rat and mouse adult models of CNS preconditioning using LPS, TNF- $\alpha$, or ischemia (14). The mechanisms are unclear but induction of hypoxia-inducible factor (30), nitric oxide (16,31), heat shock proteins (32), inhibition of caspases (33), and induction of the anti-apoptotic system (34) seem important in the immature brain. In our microarray analysis we found, in agreement with previous studies, an up-regulation of heat shock protein in association with LPS-induced preconditioning (unpublished observations). There was also an up-regulation of granulin and allograft inflammatory factor 1 , which is induced by cytokines and interferon.

In the adult rat, LPS preconditioning in focal cerebral ischemia could be due to its stimulation of cytokines, such as TNF- $\alpha$ expression. Hence, the brain protective effect of LPSinduced preconditioning was completely lost after neutralizing TNF- $\alpha$ by administration of TNF-binding protein (7). Furthermore, ceramide, a downstream messenger of TNF- $\alpha$ signaling, contributes to LPS-induced tolerance $(14,35)$. Preconditioning induced by LPS is also associated with the induction of TGF$\beta 1$, which has neuroprotective properties (15). Other studies suggest that up-regulation of antioxidants (superoxide dismutase) after low doses of endotoxin may be important in LPS-induced tolerance (36). To conclude, LPS demonstrates a biphasic sensitizing effect on the immature brain including a primary phase at $4-6 \mathrm{~h}$ and a secondary response at $72 \mathrm{~h}$ after administration. In contrast, LPS confers a preconditioning effect when administered $24 \mathrm{~h}$ before HI. The secondary sensitizing effect has not previously been described and may have important clinical implications.

Acknowledgments. The authors thank Mrs. Eva Cambert for technical assistance.

\section{REFERENCES}

1. Badawi N, Kurinczuk JJ, Keogh JM, Alessandri LM, O'Sullivan F, Burton PR, Pemberton PJ, Stanley FJ 1998 Intrapartum risk factors for newborn encephalopathy: the Western Australian case-control study. BMJ 317:1554-1558

2. Badawi N, Kurinczuk JJ, Keogh JM, Alessandri LM, O'Sullivan F, Burton PR, Pemberton PJ, Stanley FJ 1998 Antepartum risk factors for newborn encephalopathy: the Western Australian case-control study. BMJ 317:1549-1553

3. Grether JK, Nelson KB 1997 Maternal infection and cerebral palsy in infants of normal birth weight. JAMA 278:207-211

4. Dammann O, Leviton A 2000 Role of the fetus in perinatal infection and neonatal brain damage. Curr Opin Pediatr 12:99-104

5. Nelson KB, Grether JK 1998 Potentially asphyxiating conditions and spastic cerebral palsy in infants of normal birth weight. Am J Obstet Gynecol 179:507-513

6. Eklind S, Mallard C, Leverin AL, Gilland E, Blomgren K, Mattsby-Baltzer I, Hagberg H 2001 Bacterial endotoxin sensitizes the immature brain to hypoxic-ischaemic injury. Eur J Neurosci 13:1101-1106 
7. Tasaki K, Ruetzler CA, Ohtsuki T, Martin D, Nawashiro H, Hallenbeck JM 1997 Lipopolysaccharide pre-treatment induces resistance against subsequent focal cerebral ischemic damage in spontaneously hypertensive rats. Brain Res 748:267-270

8. Dawson DA, Furuya K, Gotoh J, Nakao Y, Hallenbeck JM 1999 Cerebrovascular hemodynamics and ischemic tolerance: lipopolysaccharide-induced resistance to focal cerebral ischemia is not due to changes in severity of the initial ischemic insult, but is associated with preservation of microvascular perfusion. J Cereb Blood Flow Metab 19:616-623

9. Rice JE 3rd, Vannucci RC, Brierley JB 1981 The influence of immaturity on hypoxic-ischemic brain damage in the rat. Ann Neurol 9:131-141

10. Mallard EC, Williams CE, Gunn AJ, Gunning MI, Gluckman PD 1993 Frequen episodes of brief ischemia sensitize the fetal sheep brain to neuronal loss and induce striatal injury. Pediatr Res 33:61-65

11. Gilland E, Bona E, Hagberg H 1998 Temporal changes of regional glucose use, blood flow, and microtubule-associated protein 2 immunostaining after hypoxia-ischemia in the immature rat brain. J Cereb Blood Flow Metab 18:222-228

12. Hedtjarn M, Leverin AL, Eriksson K, Blomgren K, Mallard C, Hagberg H 2002 Interleukin-18 involvement in hypoxic-ischemic brain injury. J Neurosci 22:59105919

13. Mallard EC, Rehn A, Rees S, Tolcos M, Copolov D 1999 Ventriculomegaly and reduced hippocampal volume following intrauterine growth-restriction: implications for the aetiology of schizophrenia. Schizophr Res 40:11-21

14. Zimmermann C, Ginis I, Furuya K, Klimanis D, Ruetzler C, Spatz M, Hallenbeck JM 2001 Lipopolysaccharide-induced ischemic tolerance is associated with increased levels of ceramide in brain and in plasma. Brain Res 895:59-65

15. Boche D, Cunningham C, Gauldie J, Perry VH 2003 Transforming growth factor-beta 1 -mediated neuroprotection against excitotoxic injury in vivo. J Cereb Blood Flow Metab 23:1174-1182

16. Puisieux F, Deplanque D, Pu Q, Souil E, Bastide M, Bordet R 2000 Differential role of nitric oxide pathway and heat shock protein in preconditioning and lipopolysaccharide-induced brain ischemic tolerance. Eur J Pharmacol 389:71-78

17. Bastide M, Gele P, Petrault O, Pu Q, Caliez A, Robin E, Deplanque D, Duriez P, Bordet R 2003 Delayed cerebrovascular protective effect of lipopolysaccharide in parallel to brain ischemic tolerance. J Cereb Blood Flow Metab 23:399-405

18. Cai Z, Pan ZL, Pang Y, Evans OB, Rhodes PG 2000 Cytokine induction in fetal rat brains and brain injury in neonatal rats after maternal lipopolysaccharide administration. Pediatr Res 47:64-72

19. Bell MJ, Hallenbeck JM 2002 Effects of intrauterine inflammation on developing rat brain. J Neurosci Res 70:570-579

20. Reyes TM, Walker JR, DeCino C, Hogenesch JB, Sawchenko PE 2003 Categorically distinct acute stressors elicit dissimilar transcriptional profiles in the paraventricula nucleus of the hypothalamus. J Neurosci 23:5607-5616

21. Coumans AB, Middelanis JS, Garnier Y, Vaihinger HM, Leib SL, Von Duering MU, Hasaart TH, Jensen A, Berger R 2003 Intracisternal application of endotoxin enhances the susceptibility to subsequent hypoxic-ischemic brain damage in neonatal rats. Pediatr Res 53:770-775
22. Lehnardt S, Massillon L, Follett P, Jensen FE, Ratan R, Rosenberg PA, Volpe JJ, Vartanian T 2003 Activation of innate immunity in the CNS triggers neurodegeneration through a Toll-like receptor 4-dependent pathway. Proc Natl Acad Sci U S A 100:8514-8519

23. Yang L, Sameshima H, Ikeda T, Ikenoue T 2004 Lipopolysaccharide administration enhances hypoxic-ischemic brain damage in newborn rats. J Obstet Gynecol Res 30:142-147

24. Wu CC, Yen MH 1997 Beneficial effects of dantrolene on lipopolysaccharide-induced haemodynamic alterations in rats and mortality in mice. Eur J Pharmacol 327:17-24

25. Cabrera R, Korte SM, Lentjes EG, Romijn F, Schonbaum E, De Nicola A, De Kloet ER 2000 The amount of free corticosterone is increased during lipopolysaccharideinduced fever. Life Sci 66:553-562

26. Choi JS, Park HJ, Cha JH, Chung JW, Chun MH, Lee MY 2003 Induction and temporal changes of osteopontin mRNA and protein in the brain following systemic lipopolysaccharide injection. J Neuroimmunol 141:65-73

27. Ajmone-Cat MA, Nicolini A, Minghetti L 2003 Prolonged exposure of microglia to lipopolysaccharide modifies the intracellular signaling pathways and selectively promotes prostaglandin E2 synthesis. J Neurochem 87:1193-1203

28. Carvey PM, Chang Q, Lipton JW, Ling Z 2003 Prenatal exposure to the bacteriotoxin lipopolysaccharide leads to long-term losses of dopamine neurons in offspring: potential, new model of Parkinson's disease. Front Biosci 8:s826-s837

29. Gidday JM, Fitzgibbons JC, Shah AR, Park TS 1994 Neuroprotection from ischemic brain injury by hypoxic preconditioning in the neonatal rat. Neurosci Lett 168:221224

30. Bergeron M, Gidday JM, Yu AY, Semenza GL, Ferriero DM, Sharp FR 2000 Role of hypoxia-inducible factor-1 in hypoxia-induced ischemic tolerance in neonatal rat brain. Ann Neurol 48:285-296

31. Gidday JM, Shah AR, Maceren RG, Wang Q, Pelligrino DA, Holtzman DM, Park TS 1999 Nitric oxide mediates cerebral ischemic tolerance in a neonatal rat model of hypoxic preconditioning. J Cereb Blood Flow Metab 19:331-340

32. Ikeda T, Ikenoue T, Xia XY, Xia YX 2000 Important role of 72-kd heat shock protein expression in the endothelial cell in acquisition of hypoxic-ischemic tolerance in the immature rat. Am J Obstet Gynecol 182:380-386

33. McLaughlin B, Hartnett KA, Erhardt JA, Legos JJ, White RF, Barone FC, Aizenman E 2003 Caspase 3 activation is essential for neuroprotection in preconditioning. Proc Natl Acad Sci U S A 100:715-720

34. Cantagrel S, Krier C, Ducrocq S, Bodard S, Payen V, Laugier J, Guilloteau D, Chalon S 2003 Hypoxic preconditioning reduces apoptosis in a rat model of immature brain hypoxia-ischaemia. Neurosci Lett 347:106-110

35. Liu J, Ginis I, Spatz M, Hallenbeck JM 2000 Hypoxic preconditioning protects cultured neurons against hypoxic stress via TNF-alpha and ceramide. Am J Physio Cell Physiol 278:C144-C153

36. Kramer BC, Yabut JA, Cheong J, JnoBaptiste R, Robakis T, Olanow CW, Mytilineou C 2002 Lipopolysaccharide prevents cell death caused by glutathione depletion: possible mechanisms of protection. Neuroscience 114:361-372 